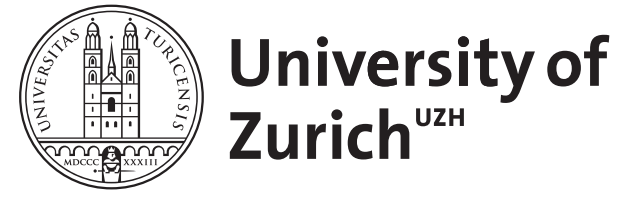

Zurich Open Repository and Archive

University of Zurich

University Library

Strickhofstrasse 39

CH-8057 Zurich

www.zora.uzh.ch

Year: 2012

\title{
Angst und Ansteckung zwischen Epidemien und Finanzkrise
}

Honigsbaum, Mark

Posted at the Zurich Open Repository and Archive, University of Zurich ZORA URL: https://doi.org/10.5167/uzh-63057

Journal Article

Published Version

Originally published at:

Honigsbaum, Mark (2012). Angst und Ansteckung zwischen Epidemien und Finanzkrise. Schweizerische Ärztezeitung, 93(7):262-264. 


\section{Angst und Ansteckung zwischen Epidemien und Finanzkrise}

\section{Mark Honigsbaum}

Journalist und Wissenschaftlicher Mitarbeiter am Medizinhistorischen Institut der Universität Zürich

Der Text wurde aus dem Englischen übersetzt.
Korrespondenz:

Mark Honigsbaum, PH.D

Medizinhistorisches Institut und Museum der Universität Zürich Hirschengraben 82 CH-8001 Zürich

Tel. 0446342196

m.honigsbaum[at]mhiz.uzh.ch
Der Film «Planet der Affen: Prevolution», der letztes Jahr in die Kinos kam, hat ein ganz spezielles Ende. Während bereits der Abspann läuft, sieht man ein Flugzeug und seinen mit einem tödlichen Gehirnvirus infizierten Piloten. Beim Abflug in San Francisco hatte man schon sein blutiges Husten beobachten können. Man erahnt, dass auf die Menschheit etwas Unheilvolles zukommt, denn der Weg des Flugzeugs zunächst nach New York und anschliessend nach Frankfurt - spinnt schon bald ein Netzgewebe aus kreuz und quer sich überschneidenden Linien um den Erdball.

Rechnet man die Zahl der Linien, die allein auf einer Karte des Lufthansa-Flugplans eingezeichnet sind, hoch zehn, sind die Verbreitungsmöglichkeiten des Virus symbolisch schnell erkennbar - und gleichzeitig auch das technologische Netzwerk, das die Verbreitung von materiellen und immateriellen Dingen in Prevolution ermöglicht. Und nebenbei ist so der Fortsetzungsfilm mit dem kurz bevorstehenden Weltuntergang geschickt angekündigt.

Seitdem in den frühen Achtzigerjahren behauptet wurde, dass der Air-Canada-Flugbegleiter Gaetan Dugas - auch Patient Zero genannt - angeblich Aids nach Nordamerika eingeschleppt hat, sind neuartige Ansteckungsängste schwer einzudämmen. Dank des internationalen Flugverkehrs und der permanenten Anforderungen der globalen Märkte sind aus dem Regenwald stammende tödliche Krankheitserreger nur so weit von einer Metropole entfernt wie eine Anfahrt per LKW, Bahn oder Flug. In unserer Zeit bedeutet dies, dass sie nahezu augenblicklich dort sein können.

In neueren Kinofilmen wie Prevolution oder Contagion (über das Verbreiten eines neuartigen grippeähnlichen Virus) geht es allerdings nicht so sehr um den feindlichen Einfall einer nicht sofort erkennbaren Erkrankung in unsere als keimfrei betrachtete Umwelt. Dem Contagion-Regisseur Steven Soderbergh etwa geht es vielmehr um das verheerende Chaos, das durch das besagte technologische Netzwerk im 21. Jahrhundert angerichtet werden kann.

\section{Es geht um Angst}

Natürlich findet sich das Warnschild für biologische Gefahr auch auf den Werbeplakaten von Contagion, aber es geht eher um die Gefährdung durch die Infektiosität der Panik. Man könnte dies auch als eine moralische oder emotionale Angst vor dem «Contagion» beschreiben, und genau dies hat Soderberghs kreative Ader angeregt, denn der englische Untertitel des Films lautet nothing spreads like fear.

Die Angst oder wenigstens das Geld, das durch Angst verdient werden kann, bildet auch das Kernstück des neuen Buchthrillers von Robert Harris The Fear Index, der gerade auf Deutsch unter dem schlichten Titel «Angst» erschienen ist [1]. Der Autor nimmt eine Anleihe bei Charles Darwins The Expression of Emotions in Man and Animals (1872), um den Leser in einem nicht gerade subtilen Handlungsablauf auf den bevorstehenden Nervenkitzel vorzubereiten: «Das Herz zieht sich schnell und heftig zusammen, so dass es gegen die Rippen schlägt oder anstösst ...», schreibt Harris, Darwin zitierend, kurz bevor ein Eindringling in das Haus seiner Hauptfigur, Dr. Alexander Hoffmann, hereinplatzt. «Wenn die Furcht auf den höchsten Gipfel steigt, dann wird der fürchterliche Schrei des Entsetzens gehört. Grosse Schweisstropfen stehen auf der Haut.»

\section{Es gilbt keine Garantie, dass Viren sich so verhalten, wie die Mathematik es voraussagt.}

Dennoch ist es nicht die Physiologie der Angst, die Harris interessiert, sondern vielmehr die Angst aus der Perspektive der Psychologie und der Epidemiologie. Harris' Romanfigur Hoffmann, ein brillanter Physiker, hat den Dienst im CERN quittiert und in Genf einen Hedge Fonds gegründet. Dafür entwickelte er einen Algorithmus unter dem Decknamen VIXAL-4, um die Finanzmärkte zu beobachten.

Von einem Schriftsteller, der wie Harris ständig am Puls des Zeitgeistes schreibt, ist wohl nichts anderes zu erwarten, als dass er in seinen Roman Begriffe wie Bogeys, Quants und Swaps einfliessen lässt. Lässt man diesen Finanzjargon jedoch ausser Acht, ist das Prinzip von VIXAL-4 klar: Es ist eine Finanztechnik, die Aktienleerverkäufe gerade dann empfiehlt, wenn Aufregung in den Märkten herrscht. Sozusagen als Anlagetipp beschreibt er, wie die Furcht das globale Marktgeschehen stärker bestimmt als je zuvor. VIXAL-4 wird in seinem Roman so zu einer Art Lizenz, Geld zu drucken.

Warum aber sollte gerade heutzutage grössere Furcht herrschen als zum Beispiel während des Kalten 


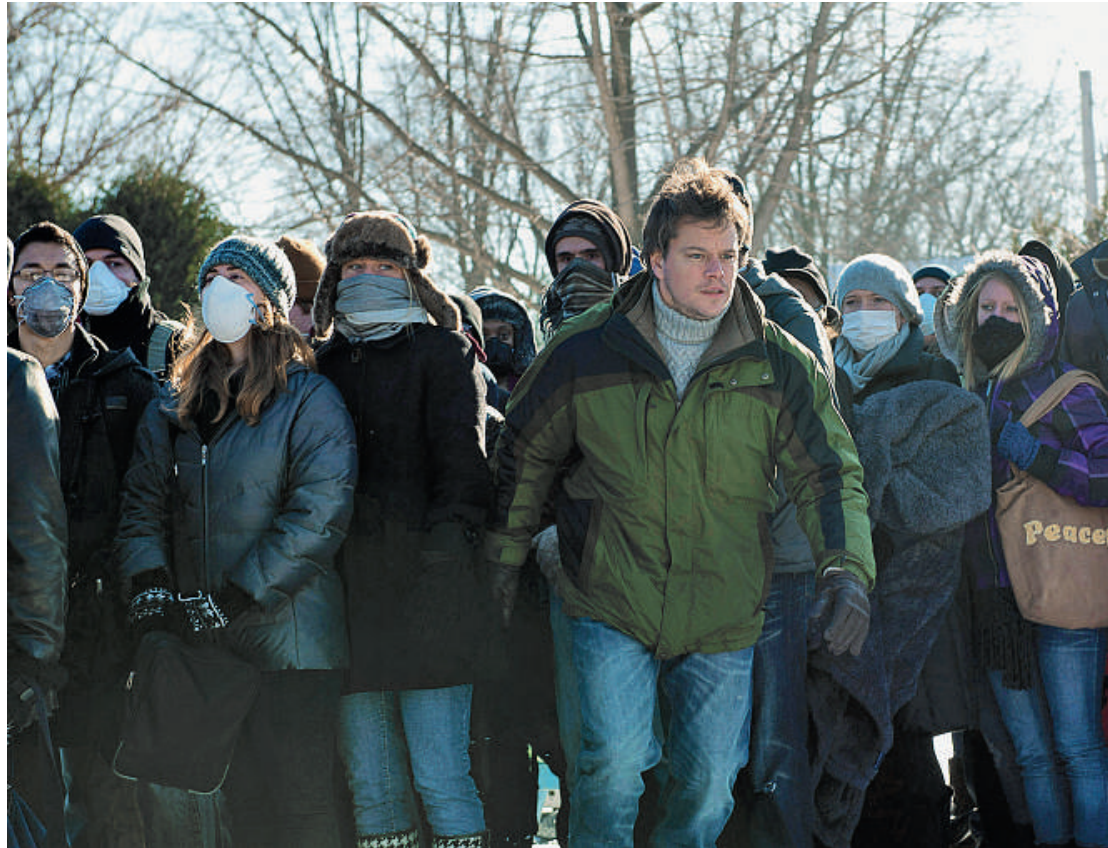

Im Film «Contagion» geht es nicht nur um ein extrem ansteckendes Virus, sondern auch um die Gefährdung durch die Infektiosität der Panik. (c) 2011 Warner Bros. Entertainment Inc.
Epidemiologie anwenden? Denn Ansteckung ist nicht das Gleiche wie Übertragung. Darüber hinaus ist eine Kontamination durch ein lebendes Virus nicht mit einer «virtuellen» Infektion eines verselbständigten Computer-Codes zu vergleichen. Und das tun wir, wenn wir Angst auf Algorithmen reduzieren, die Finanzmärkte «infizieren».

Wenn man sich, wie bisher, jedoch auf den Ansteckungseffekt im epidemiologischen Sinn bezieht, der sich dann als Metamorphose im nichtbiologischen Kontext entwickelt, kann sich eine solche Vorstellung eher als zu abstrakt herausstellen und das ganze Gerede von Computerviren und «digitaler Epidemie» lässt dann das übersehen, was sich eigentlich in Informatik-Netzwerken abspielt.

Es gibt auch noch einen weiteren Zusammenhang; ähnlich wie im Umkreis der Informationssicherheit werden biologische Bilder angewandt, um Computerviren zu verstehen und um somit Computer-Immunsysteme entwickeln zu können. Und in auf mathematischen Formeln basierenden epidemiologischen Studien werden Statistik und Wahrscheinlichkeitsrechnungen dazu genutzt, die Entwicklung von Epidemien zu untersuchen.

\section{Die biologische Ansteckung kann} nicht mit derjenigen der virtuellen

\section{Welt des Internets gleichgesetzt} werden. Stimmungsschwankungen durch beispiellose Informationsverbreitung per Internet.» Für Harris ist es also die Digitalisierung selbst, die eine epidemische Ausbreitung der Angst fördert.

Auch Soderberghs Contagion-Film greift den Gedanken auf, dass unser digitalisiertes Leben dazu tendiert, die Ausbreitung von Angst und anderen ansteckenden Emotionen zu unterstützen. Indem sich im Film ein Blogger (gespielt von Jude Law) in eine Konspirationstheorie hereinsteigert, um die Wahrheit über das Virus aufzudecken, und sich die Fachleute im Center for Disease Control (CDC) in Atlanta die Köpfe zerbrechen, inwieweit sie die Öffentlichkeit über die Epidemie unterrichten müssen, legt Soderbergh nahe, dass es in unserer technologisch-vernetzten Umwelt mittlerweile fast unmöglich ist, eine Hysterie in Grenzen zu halten. Stattdessen verselbständigen sich die von Bloggern und in Facebook \& Co. verbreiteten Gerüchte und Halbwahrheiten in immer neuer Aufmachung. Mit dem Effekt, dass die Angst zu einer Art Virus wird und sich, ähnlich einer DNAReplikation im menschlichen Körper, immer wieder replizieren wird und Zweifel und Misstrauen verbreitet, wo immer sie auftritt.

Biomedizinische Metaphern und Informatik Aber ist es richtig, wenn wir biomedizinische Metaphern im Zusammenhang mit Informatik und Sozial-
Dank des World Health Organization's Global Outbreak Alert and Response Network (GOARN) und einem elektronisch gesteuerten Berichtsystem über Erkrankungen, wie zum Beispiel von ProMED, werden derzeit Suchmaschinen routinemässig eingesetzt, um das Internet auf ungewöhnliche Krankheitsausbrüche zu durchforsten, während gleichzeitig andere Computer eingesetzt werden, um Epidemieausbrüche zu simulieren.

Daraus ergibt sich, was der Medientheoretiker Eugene Thacker einen «Wettstreit» nennt, der in Realzeit zwischen Netzwerken ausgeführt wird: auf der einen Seite ein biologisches Netzwerk, das Infektionen erkennt, die darüber hinaus durch moderne Transporttechnologien begünstigt werden; auf der anderen Seite ein Informationsnetzwerk, das einen raschen Datenaustausch zwischen Instituten ermöglicht [2].

Dahinter steht demnach der Gedanke, dass bestimmte Verhaltensweisen von Computern mit der Biologie verstehbar gemacht werden können, während Ansteckungsgefährdungen durch Mathematik und Informatik verständlich werden. Obwohl solche Beobachtungssysteme von Krankheiten wirkungsvoll funktionieren - bestätigt durch das Beispiel der ge- 
rade noch rechtzeitigen Reaktion auf SARS im Jahre 2003 -, könnten sie sich auch als Eigentore erweisen.

Interessanterweise ist dies nicht nur eine Frage exakter Daten. Durch die Epidemiologie lassen sich zwar Statistiken erarbeiten, weil sie auf tatsächlichen Gegebenheiten basieren, wirkliche Viren verhalten sich allerdings eher auf ungeregelte Weise. Unabhängig davon, wie genau vorhandene Daten sein mögen, gibt es keine Garantie darauf, dass Viren sich so verhalten, wie die Mathematik es voraussagt - daher die ungenauen Prognosen über Sterblichkeitsraten anlässlich der Schweinegrippe im Jahr 2009. tigen Volatilitäten dort. Und wenn es noch so nahe liegt, diese Volatilität der Digitalisierung zuzuschreiben, ist die Ansicht von Harris doch sicherlich falsch, wenn er meint, das Internet trage dazu bei, «menschliche Stimmungsschwankungen» zu verschärfen. Vielmehr sei solche Volatilität, so heisst es in einem kürzlich erschienenen Bericht über Contagion in Financial Networks der Bank of England, auf zunehmend komplexere Netzwerke und eine Vernetzung unter den Finanzinstituten zurückzuführen [3].

Wenn Defaults, also Zahlungsausfälle, sich über das gesamte Finanzsystem verbreiten, so argumentie-

\section{Das enge Vernetztsein macht uns für Ansteckungsprozesse emotionaler Natur empfänglich und damit verletzbar.}

Gerade solche oft fehlerhaften Voraussagen haben die öffentliche Meinung zunehmend misstrauisch gegenüber der Wissenschaft gemacht. Dies erklärt auch, weshalb Konspirationstheorien, wie sie der erwähnte Blogger Alan Krunwiede in Contagion repräsentiert, grossen Zuspruch finden. Als obsessiver Blogger verbringt er einen Grossteil des Films damit, dass er das CDC bezichtigt, mit den grossen Pharmaunternehmen unter einer Decke zu stecken, und verteilt gleichzeitig Flugblätter über homöopathische Mittel gegen das Virus. Natürlich ist hier eine gewisse Ironie zu erkennen, denn unter Gesichtspunkten der Sozialepidemiologie ist Misstrauen ansteckend. Mit Hilfe von Twitter, Facebook und anderen sozialen Medien verbreiten sich Konspirationstheorien so rasch wie alle anderen Viren und entfachen Skepsis, Angst und manchmal auch Hass auf Autoritäten, ganz gleich, ob damit nun ein WHORepräsentant in Genf oder ein Banker in Zürich gemeint ist.

Genauso wie die biologische Ansteckung nicht mit derjenigen der virtuellen Welt des Internets gleichgesetzt werden kann, sollte man Computerviren nicht mit ihrem biologischen Pendant in einen Topf werfen. Das nämlich ist die Falle, in die Epidemiologen geraten, wenn sie mit Modellen der Mathematik Ansteckungsgefahren von Mensch zu Mensch erklären wollen

Nur deshalb, weil das CDC den Sexualkontakt von Gaetan Dugas und an HIV infizierten Männern in San Francisco, Los Angeles und anderen Städten in Amerika in den frühen Achtzigerjahren rückverfolgen konnte, war Dugas nicht unbedingt Patient Zero. So viel man weiss, gibt es noch weitere Patients Zero. Sie sind lediglich Knotenpunkte in einem grossen Netz.

Der Rückgriff auf Metaphern eines Contagions auf den Finanzmärkten erklärt auch nicht die derzei- ren die Autoren des Berichts, dann verringert ein dichtes finanzielles Netz von Abhängigkeiten, dass immense Verluste, wie sie im Fall der Lehman Brothers vorkamen, andere Banken und Investmentgesellschaften mitreissen. Gleichzeitig machen diese Abhängigkeiten es aber wahrscheinlicher, dass die Ausbreitung von Zahlungsproblemen über den Ansteckungseffekt weiter gestreut ist. Das sich daraus ergebende Resultat nennen die Autoren eine robust-yet-fragile tendency: Die Wahrscheinlichkeit einer epidemischen Ausbreitung solcher Finanzprobleme ist gering. Sollte der Fall aber eintreten, würden sie sich sehr weit verbreiten. In dieser epidemischen Situation der Finanzmärkte befinden wir uns gerade. Dies erklärt auch, warum FTSE, Dow und Nikkei immer weiter fielen, als die europäischen Regierungen den Bail-Out Griechenlands im letzten Herbst so zögerlich angingen.

Aus diesem Grund ist es heute eine viel grössere Herausforderung, das Vertrauen in den Finanzmarkt wiederherzustellen, als dies 1932 der Fall war, als Franklin D. Roosevelt seine berühmte Rede an die amerikanische Bevölkerung hielt, sie hätte nothing to fear, but fear itself. Heutzutage ist es das enge Vernetztsein untereinander, das uns für solche Ansteckungsprozesse emotionaler Natur empfänglich und damit verletzbar macht. In diesem Sinne sind die Netzwerke die eigentlichen Quellen von Unbeständigkeit und Angst.

\section{Literatur}

1 Harris R. Angst. München: Heyne; 2011.

2 Thacker E. Living Dead Networks. Fibreculture (Onlinezeitschrift). 4; 2005. http://four.fibreculturejournal.org/fcj-018-living-dead-networks/

3 Gai P, Kapadia S. Contagion in Financial Networks. Bank of England Working Paper No. 383. www. bankofengland.co.uk/publications/workingpapers/ wp383.pdf 